\title{
Creep Properties of Walikukun (Schouthenia ovata) Timber Beams
}

\author{
Awaludin, A. ${ }^{*}$, Ngudiyono ${ }^{2}$, and Basuki, A. ${ }^{3}$
}

\begin{abstract}
This study presents an evaluation of creep constants of Walikukun (Schouthenia ovata) timber beams when rheological model of four solid elements, which is obtained by assembling Kelvin and Maxwell bodies in parallel configuration, was adopted. Creep behavior obtained by this method was further discussed and compared with creep behavior developed using phenomenological model of the previous study. Creep data of previous study was deformation measurement of Walikukun beams having cross-section of $15 \mathrm{~mm}$ by $20 \mathrm{~mm}$ with a clear span of $550 \mathrm{~mm}$ loaded for three weeks period under two different room conditions: with and without Air Conditioner. Creep behavior given by both four solid elements model and phenomenological (in this case are power functions) had good agreement during the period of creep measurement, but they give different prediction of creep factor beyond this period. The power function of phenomenological model could give a reasonable creep prediction, while for the four solid elements model a necessary modification is required to adjust its long-term creep behavior.
\end{abstract}

Keywords: Creep; four solid element creep model; Walikukun timber; rheological model; phenomenological model.

\section{Introduction}

Creep is generally defined as an increase of deflection or deformation under a constant load. It reflects the long-term behavior of a material and is very significant in fiber-based materials such as timber. This creep phenomenon is well observed, for instance in building elements such as bending deformation of beams and axial deformation of wooden (shear) walls. Structural creep occured in high rise buildings causes dramatic change of end moment of beams [1]. Understanding creep behavior is necessary to deliver a proper design throughout desirable service life. In contrast, failure to understand creep behavior will lead to shortened service life as well as structural instability including $P$ - $\Delta$ effect and longterm stress redistribution [2-5]. There are two ways to predict long-term creep of timber: through phenomenological model and mechanical or rheological model.

1 Research Group of Innovative Sustainable Infrastructure Materials and Construction Technologies, Department of Civil and Environmental Engineering, Gadjah Mada University, Grafika Street \# 2, UGM campus, Sleman, Yogyakarta, 55281, INDONESIA

2 Department of Civil Engineering, Faculty of Engineering, Mataram University, Majapahit street \# 62, Nusa Tenggara Barat, 83126, INDONESIA

${ }^{3}$ SMARTWood Research Group, Department of Civil Engineering, Faculty of Engineering, Sebelas Maret University, Ir Sutami street \# 36A, Surakarta, 57126, INDONESIA

*Corresponding author; e-mail: ali.awaludin@ugm.ac.id

Note: Discussion is expected before November, $1^{\text {st }} 2016$, and will be published in the "Civil Engineering Dimension" volume 19, number 1, March 2017.

Received 04 February 2016; revised 14 August 2016; accepted 17 August 2016.
The first method is utilizing mathematical function to best fit the short-term experimental creep data, while the second method is represented by a set of springs and dashpots whose constants are searched to best fit the short-term experimental creep data. In the rheological model, timber is assumed to behave as a viscoelastic material.

This study is aimed to examine the creep phenomenon of Indonesian Walikukun (Schouthenia ovata) timber species under two different indoor environments and to provide the constants required by rheological and phenomenological models. In addition, discussion on these two different models to predict the long-term creep phenomenon is presented.

\section{Creep Models}

The well accepted mechanical model to predict creep of timber is the four solid elements, or known as Burger model as shown in Figure 1(a). This model is derived by assembling Kelvin and Maxwell bodies in parallel configuration [3]. Having two dashpot elements, one in Kelvin body and another in Maxwell body, this model is capable to predict both primary and secondary creep. Governing equation to this four solid elements model is as follows [5],

$$
P+\left(\frac{\eta_{v}}{k_{e}}+\frac{\eta_{v}}{k_{k}}+\frac{\eta_{k}}{k_{k}}\right) \frac{d P}{d t}+\frac{\eta_{v} \eta_{k}}{k_{e} k_{k}} \frac{d^{2} P}{d t}=\eta_{v} \frac{d u}{d t}+\frac{\eta_{v} \eta_{k}}{k_{k}} \frac{d^{2} u}{d t}
$$

where $P$ is applied load, $u$ is element deformation, $k_{\mathrm{e}}$, $k_{\mathrm{k}}, \eta_{\mathrm{v}}$, and $\eta_{\mathrm{k}}$ are the constants of the four solid elements model shown in Figure 1. The creep behavior of the Burger model under constant load $P_{0}$ 
can be obtained by solving this second order differential equation using Laplace transformation method [5], taking into consideration the following initial conditions at $t_{0}=0$ :

$$
\begin{aligned}
& u_{e}=\frac{P_{0}}{k_{e}} \\
& u_{v}=u_{k}=0
\end{aligned}
$$

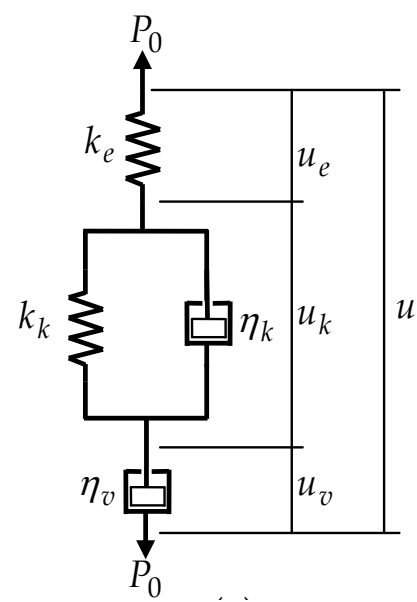

(a)

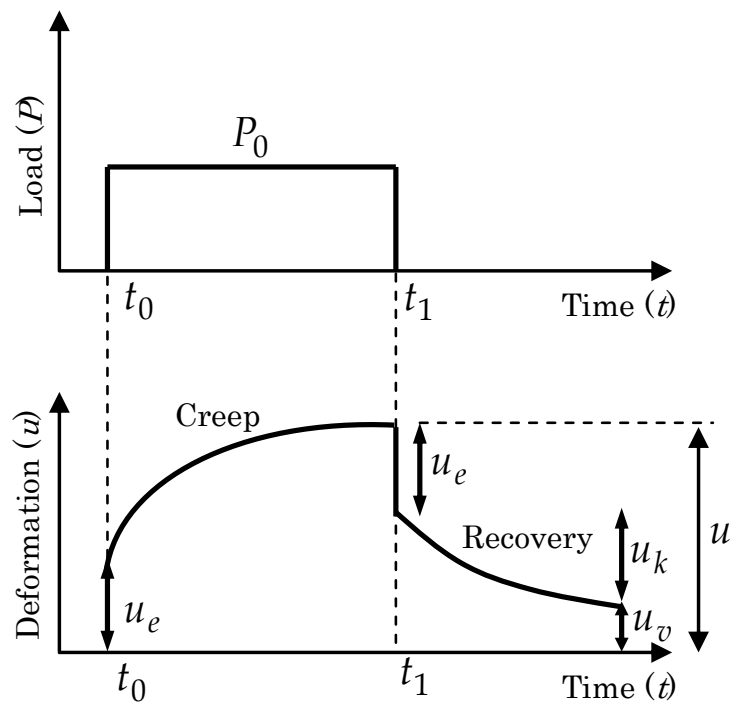

(b)

Figure 1. Creep Model for Viscoelastic Material: (a) Four Solid Elements Creep Model; and (b) Typical Generated Creep Behavior [3]

Solution of the above equation is given as,

$u(t)=\beta_{1}+\beta_{2}\left(1-e^{-\left(\beta_{3}\right) t}\right)+\beta_{4} t$

where

$\beta_{1}=P_{0} / k_{e}$

$\beta_{2}=P_{0} / k_{k}$

$\beta_{3}=k_{k} / \eta_{k}$

$\beta_{4}=P_{0} / \eta_{v}$ $\beta_{1}$ represents initial elastic deformation associated with the spring constan $k_{e} ; \beta_{2}$, and $\beta_{3}$ correspond to delayed elastic or recoverable creep component and are associated with the combined effect of the spring constant $k_{k}$ and the dashpot constant $\eta_{k}$, and finally $\beta_{4}$ corresponds to irrecoverable creep component contributed by the dashpot constant $\eta_{v}$ [6-9]. If the load $P_{0}$ is removed at time $t$ equal to $t_{1}$, the creep recovery behavior of the Burger model can be derived from Equation 1 and superposition principle by considering that at $t$ equal to $t_{1}$ and constant load $P$ is taken as $-P_{0}$. This will give:

$$
u(t)=\beta_{2}\left(e^{\left(\beta_{3}\right) t_{1}}-1\right) e^{\left(-\beta_{3}\right) t}+\beta_{4} t_{1}
$$

Typical creep and creep recovery behavior of Burger model can be seen in Figure 1(b). Recently, Ma et al. [10] based on their creep test results slightly modified Equation 3 proposed Equation 6. Here the constant $\lambda$ is generally less than 1.0.

$u(t)=\beta_{1}+\beta_{2}\left(1-e^{-\left(\beta_{3}\right) t}\right)+\beta_{4} t^{\lambda}$

\section{Creep Data [11]}

Creep data test used in this study was provided by Erlitasari [11] during her undergraduate thesis in the Civil Engineering and Environmental Engineering Department, Gadjah Mada University, Indonesia. In her work, she measured deflection of Walikukun timber beams (average moisture content $16 \%$; average specific gravity 0.95 ) having crosssection of $15 \mathrm{~mm}$ by $20 \mathrm{~mm}$ with a clear length of $550 \mathrm{~mm}$ under one constant load at mid-span for three weeks period. Schematic of Erlitasari's creep test is illustrated in Figure 2 where continuous measurement of mid-span beam deflection, room temperature, and relative humidity $(\mathrm{RH})$ was carried out. The test was conducted in two different room conditions: equipped with and without Air Conditioner (AC). Measurement of room temperature and $\mathrm{RH}$ in this two different room conditions during the test are presented in Figure 3. Temperature in these two room conditions are about the same, which is $27 \pm 1^{\circ} \mathrm{C}$, while relative humidity in the room equiped with $\mathrm{AC}$ (between $69 \%$ and $91 \%$ ) is slightly higher but more stable than that in the room without AC (between 54\% and 83\%).

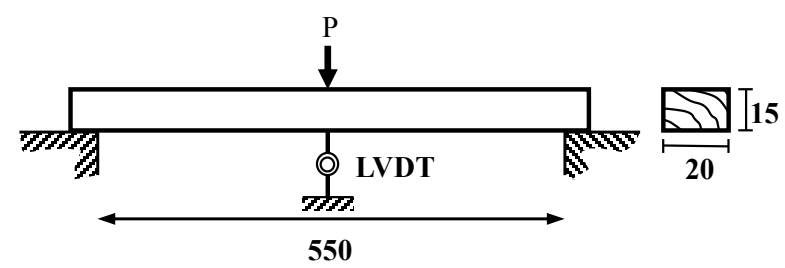

Figure 2. Schematic of Creep Measurement Carried Out by Erlitasari [11] (unit in $\mathrm{mm}$ ) 


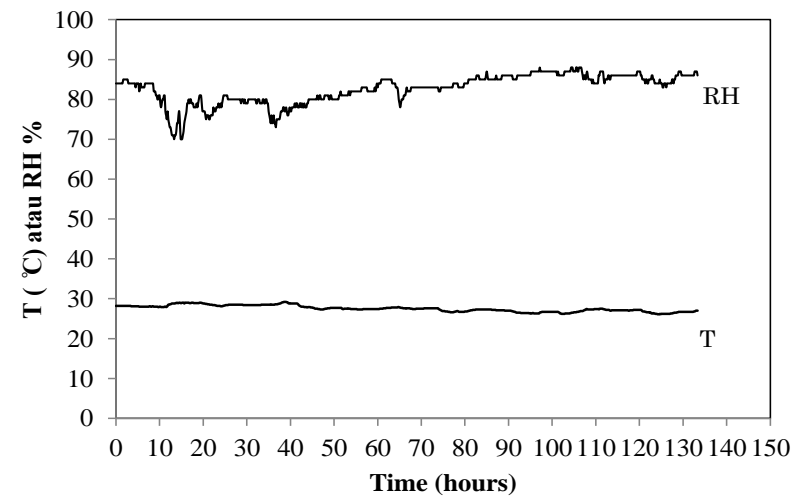

(a)

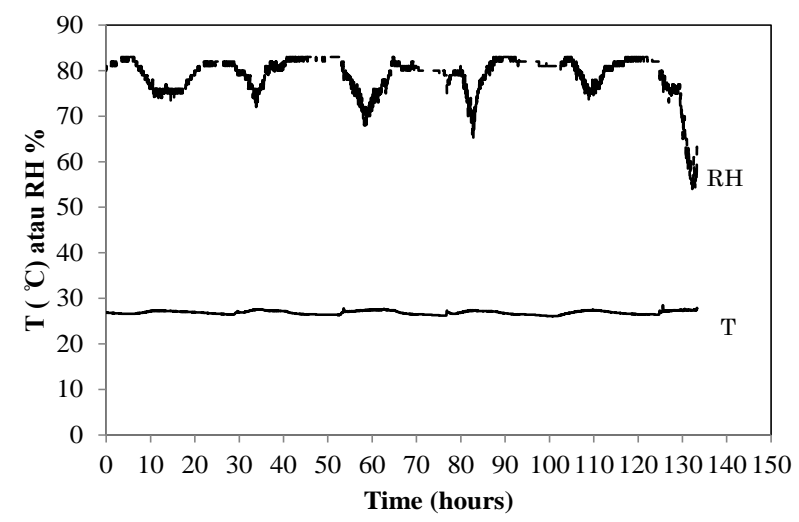

(b)

Figure 3. RH and Temperature Measurement During Creep Test: (a) Room Equiped with AC (b) Room without $\mathrm{AC}[11]$.

Erlitasari [11] loaded the beams at three different constant loads: $100 \mathrm{~N} ; 175 \mathrm{~N}$; and $250 \mathrm{~N}$, which respectively, correspond to stress levels of $30 \%, 50 \%$, and $70 \%$ of the bending load that causes failure in one month. Erlitasari did not provide further explanation of choosing this one-month failure, load as the basis in determination the stress level for creep measurement. Two beam specimens were prepared per each load level. Creep behavior and creep factor obtained from the measurement along with Erlitasari`s proposed equations are presented in Figures 4, 5, and 6 for the three different load levels. Creep factor defined in Equation 7 is the ratio of creep deformation, which is deformation developed from $t_{0}$ to $t_{1}$, to elastic or instantaneous deformation.

Creep Factor $=1+\frac{\left(\delta_{t 1}-\delta_{t 0}\right)}{\delta_{t 0}}$

Erlitasari`s proposed equation was derived based on phenomenological model where she found that power function best fitted the test data in general. As indicated by Figures. 4, 5, and 6, creep factor of the beam specimens kept in the room equiped with $\mathrm{AC}$ is less than that of the beam specimens kept in the room without $\mathrm{AC}$.

\section{Simulation Results and Discussion}

Equations 3 and 5 were solved simultaneously using Toolbox Solver program available in Microsoft Excel
[12] to best fit the creep data test of Erlitasari [11]. This Solver program uses iteration method to find coefficients of the equation that best fit the test data or producing the least of sum of square of error. These coefficients are summarized in Table 1 for three different load levels under two different room conditions obtained from two replicates. $\beta_{1}$ in the equations which defines the instant deformation (initial elastic deformation) increases in proportion to the load level, especially Specimen \# 1. In the case of Specimen \# 2, the magnitude of coefficient $\beta_{1}$ at load levels $175 \mathrm{~N}$ and $250 \mathrm{~N}$ are much greater than what we expect assuming linearly in proportion to the load level. In general, coefficients $\beta_{2}$ and $\beta_{3}$ increase as the function of load level as well though their magnitudes derived from two different room conditions are different one to another. The coeffient $\beta_{4}$ is found to be higher for a higher load level, but it is about the same magnitude for two different room conditions (see Table 1). Here we can see that a very good agreement was found between the experimental creep and its prediction developed by Equation 2, indicated by coefficient of correlation $\left(\mathrm{R}^{2}\right)$ close to one. This is an important consideration for creep prediction in the future [6].

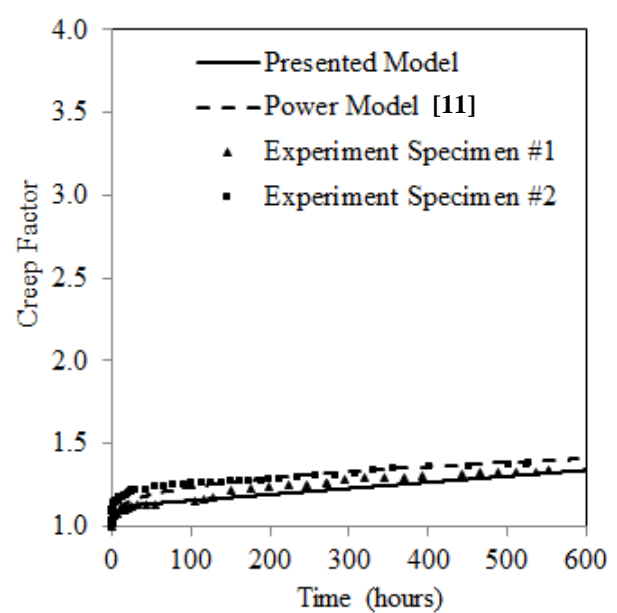

(a)

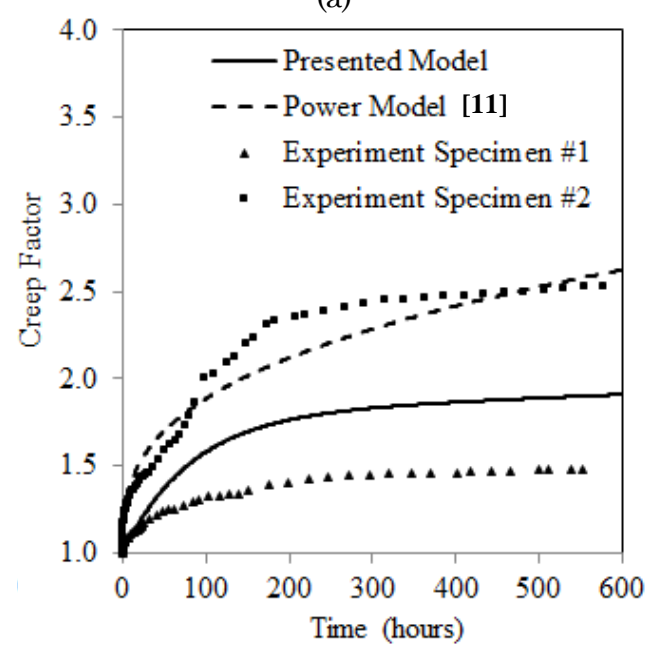

(b)

Figure 4. Creep Factor of Walikukun Beams Stress Level 30\%: (a) Room Equiped with AC; (b) Room without AC 


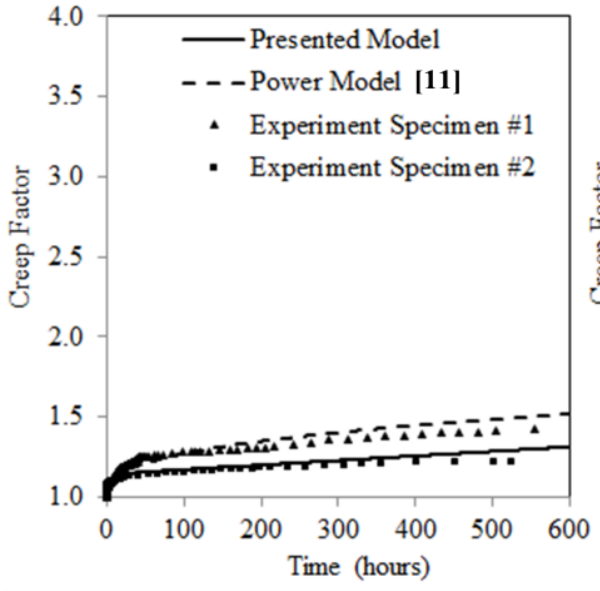

(a)

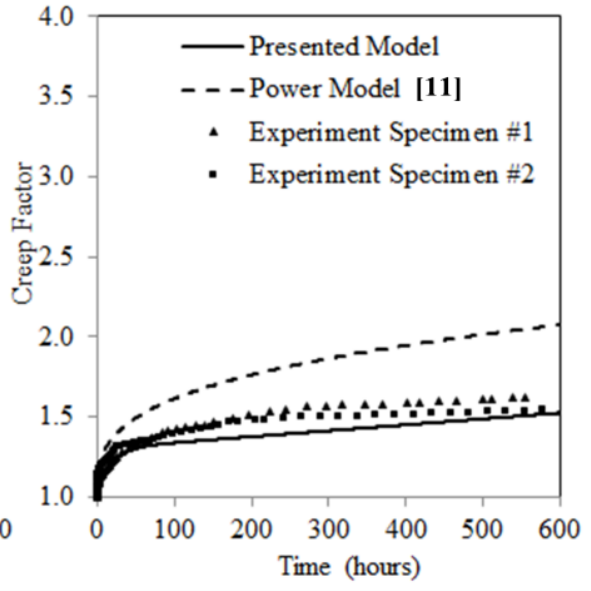

(b)

Figure 5. Creep Factor of Walikukun Beams Stress Level 50\%: (a) Room Equiped with AC; (b) Room without AC

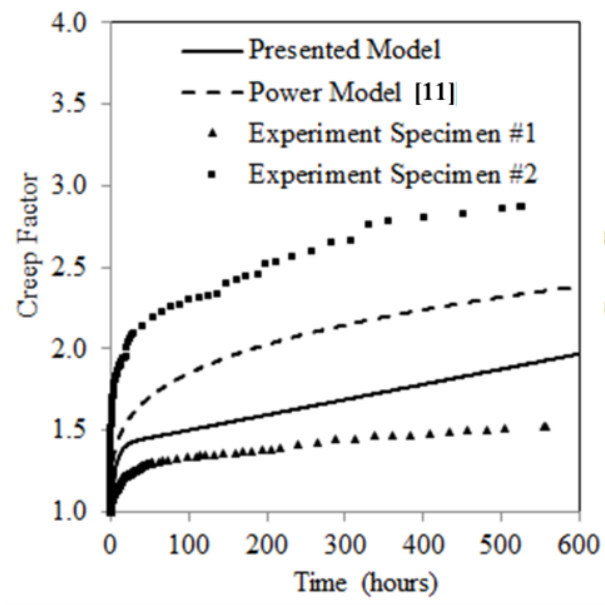

(a)

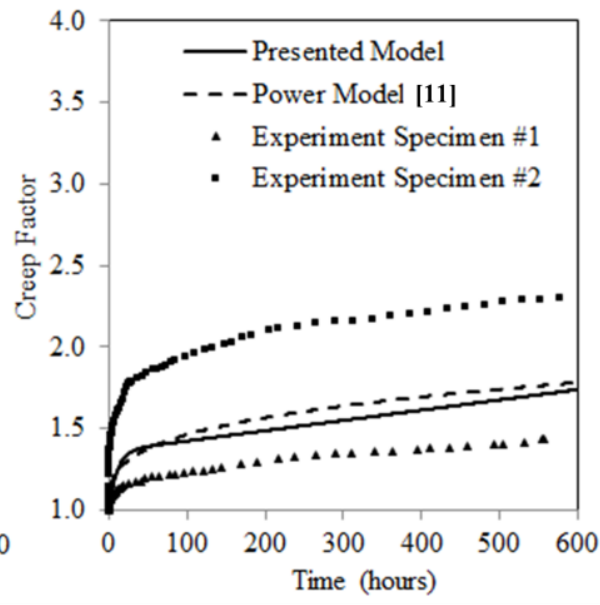

(b)

Figure 6. Creep Factor of Walikukun Beams Stress Level 70\%: (a) Room Equiped with AC; (b) Room without AC

Table 1. Coefficients of Equation 2 Obtained from Toolbox Solver Program

\begin{tabular}{cccccccc}
\hline Room condition & Load level & Specimen & $\beta_{1}$ & $\beta_{2}$ & $\beta_{3}$ & $\beta_{4}$ & $\mathrm{R}^{2}$ \\
\hline Equiped with AC & \multirow{2}{*}{$30 \%$} & $\# 1$ & 5.398 & 0.542 & 0.056 & 0.002 & 0.981 \\
& & $\# 2$ & 3.223 & 0.479 & 0.214 & 0.001 & 0.965 \\
& \multirow{2}{*}{$50 \%$} & $\# 1$ & 8.509 & 1.655 & 0.059 & 0.003 & 0.966 \\
& \multirow{2}{*}{$70 \%$} & $\# 2$ & 8.062 & 0.714 & 0.206 & 0.002 & 0.954 \\
& & $\# 1$ & 14.109 & 3.127 & 0.062 & 0.007 & 0.993 \\
\hline Not-equiped with AC & \multirow{2}{*}{$30 \%$} & $\# 1$ & 10.656 & 6.974 & 0.245 & 0.017 & 0.977 \\
& \multirow{2}{*}{$50 \%$} & 4.752 & 1.514 & 0.016 & 0.001 & 0.993 \\
& \multirow{2}{*}{$70 \%$} & $\# 1$ & 6.109 & 6.292 & 0.009 & 0.001 & 0.986 \\
& & $\# 2$ & 6.554 & 2.360 & 0.028 & 0.003 & 0.990 \\
& & $\# 1$ & 11.798 & 1.857 & 0.087 & 0.002 & 0.964 \\
& & $\# 2$ & 15.814 & 8.164 & 0.065 & 0.005 & 0.985 \\
\end{tabular}

Figure 4 shows the creep factor given by the Equation 2 along with the creep test data and power function proposed by Erlitasari [11]. In comparison to the Erlitasari's proposed power function, four solid elements model described in Equation 3 gave better agreement to the average creep data tests of both two room conditions, equiped with and without AC, as it has lower sum of squared errors as indicated in Table 2. The creep constants of four solid elements model presented in Figures. 4, 5, and 6 are summarized in Table 3 where each data is an average of the two replicates. 
Table 2. Sum of Squared Errors (SSE) of the Models

\begin{tabular}{|c|c|c|c|c|c|c|}
\hline \multirow[t]{2}{*}{ Room condition } & \multirow[t]{2}{*}{ Load level } & \multirow[t]{2}{*}{ Specimen } & \multicolumn{2}{|c|}{ Power Model [11] } & \multicolumn{2}{|c|}{ Presented Model } \\
\hline & & & SSE & Mean SSE & SSE & Mean SSE \\
\hline \multirow[t]{6}{*}{ Equiped with AC } & $30 \%$ & $\# 1$ & 0.099 & \multirow{2}{*}{0.108} & 0.118 & \multirow{2}{*}{0.188} \\
\hline & & $\# 2$ & 0.118 & & 0.257 & \\
\hline & $50 \%$ & $\# 1$ & 0.147 & \multirow{2}{*}{0.468} & 0.078 & \multirow{2}{*}{0.100} \\
\hline & & $\# 2$ & 0.789 & & 0.123 & \\
\hline & $70 \%$ & $\# 1$ & 31.640 & \multirow{2}{*}{21.852} & 0.823 & \multirow{2}{*}{6.444} \\
\hline & & $\# 2$ & 12.065 & & 12.065 & \\
\hline \multirow[t]{6}{*}{ Not-equiped with $\mathrm{AC}$} & $30 \%$ & $\# 1$ & 19.829 & \multirow{2}{*}{10.356} & 0.198 & \multirow{2}{*}{2.260} \\
\hline & & $\# 2$ & 0.883 & & 4.323 & \\
\hline & $50 \%$ & $\# 1$ & 2.743 & \multirow{2}{*}{3.635} & 0.294 & \multirow{2}{*}{0.647} \\
\hline & & $\# 2$ & 4.526 & & 1.000 & \\
\hline & $70 \%$ & \#1 & 2.464 & \multirow{2}{*}{8.323} & 0.128 & \multirow{2}{*}{4.472} \\
\hline & & \#2 & 14.182 & & 8.817 & \\
\hline
\end{tabular}

Table 3. Average Creep Constants of the Four Solid Elements of Walikukun

\begin{tabular}{cccccc}
\hline Room conditions & Load level & $\begin{array}{c}k_{\mathrm{e}} \\
(\mathrm{N} / \mathrm{mm})\end{array}$ & $\begin{array}{c}k_{\mathrm{k}} \\
(\mathrm{N} / \mathrm{mm})\end{array}$ & $\begin{array}{c}\eta_{\mathrm{k}} \\
(\mathrm{N} / \mathrm{mm}-\mathrm{h} \text {-ur })\end{array}$ & $\begin{array}{c}\eta_{\mathrm{v}} \\
(\mathrm{N} / \mathrm{mm}-\mathrm{hour})\end{array}$ \\
\hline Equiped with AC & $30 \%$ & 24.77 & 196.78 & 2148.72 & 0.66 \\
& $50 \%$ & 21.14 & 175.39 & 1495.47 & 0.70 \\
& $70 \%$ & 20.59 & 57.90 & 719.64 & 3.81 \\
\hline Not-equiped with AC & $30 \%$ & 20.31 & 40.97 & 2996.75 & 0.40 \\
& $50 \%$ & 26.34 & 89.89 & 1943.29 & 0.60 \\
& $70 \%$ & 18.50 & 84.55 & 1185.23 & 2.38 \\
\hline
\end{tabular}

Here the authors can evaluate quickly only the constant $k_{\mathrm{e}}$ whose magnitude must equal to (instantenous) elastic bending stiffness of Walikukun timber beams under loading configuration illustrated in Figure 2. Knowing that clear-span length is $550 \mathrm{~mm}$, beam cross section is $15 \mathrm{~mm}$ by $20 \mathrm{~mm}$, and Modulus of Elasticity is $12000 \mathrm{MPa}$ [9], elastic bending stiffness of the beam under one unit point load is $k_{\mathrm{e}}=48 E I / L^{3}=19.5 \mathrm{~N} / \mathrm{mm}$. This value is about the same with Maxwell spring constant $\left(k_{\mathrm{e}}\right)$ of the Burger model which is obtained by dividing the applied load with coefficient $\beta_{1}$ and this is found to be 18.50 to $24.77 \mathrm{~N} / \mathrm{mm}$. Previous reports also have shown that evaluation of the elastic bending stiffness of beam stuctures is straight froward from the information of Maxwell spring constant $\left(k_{\mathrm{e}}\right)$ of the Burger model [7, 12].

As the authors compare the creep constants of four solid element model found in the room equipped with $\mathrm{AC}$ to those found in the room without AC (see Table 3 ), it can be seen that all creep constants (except $\eta_{\mathrm{v}}$ ) in the room equipped with $\mathrm{AC}$ show a uniform trend where they decrease with respect to increase of load level. This is because they are kept in more constant environment with minimum fluctuation of room temperature and $\mathrm{RH}$. Common sense informs that the magnitude of these creep constants of one specimen are not comparable one to another and by nature they will be unique. The source of variation is because timber is a non-homogenous material and grading of the timber beam specimens was not performed before the test done by Erlitasari [11].

In order to investigate further these two creep models, Figure 7 presents the predicted creep factor within one year given by the power function proposed by Erlitasari [11] and the four solid elements model for $50 \%$ load level. The curves having the same constants as those in Figure 4, but extend the time $t$ up to one year or 8780 hours. Suprisingly that the curves given by the four solid elements model is higher as time $t$ increases, while the curves obtained from the power function proposed by Erlitasari nearly reach a complete stop. It is suggested that precaution is necessary when four solid elements model is used to predict the creep factor beyond the period of measurement, because in the actual condition creep factor will come to a constant value after very long period of measurement. A close look to the Equation 2, the last term is the source of this ambiguity where this term increases as the elapsed time higher. Ma et al. confirmed this drawback of the four solid element model when they measured the creep factor of Eucalyptus wood [10]. 


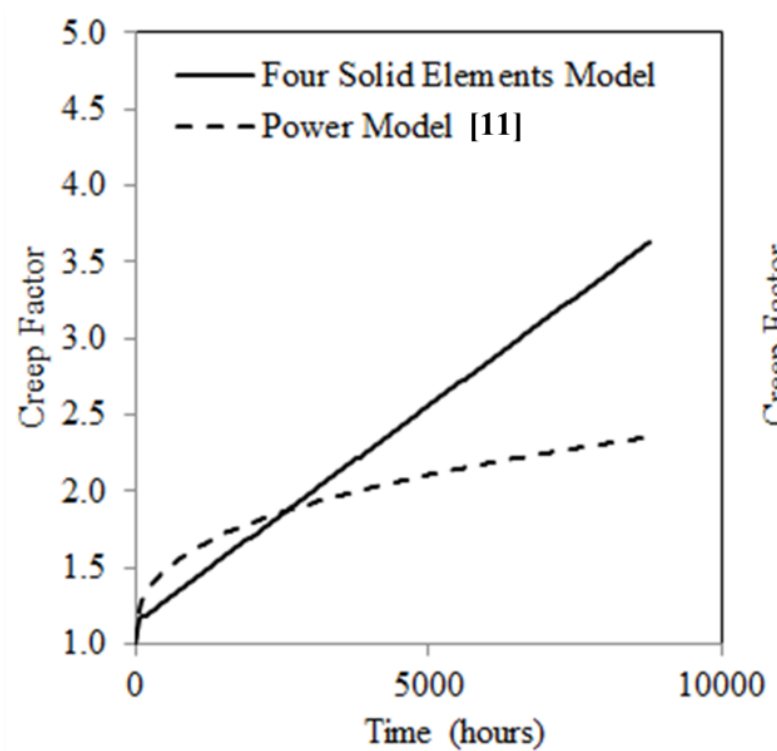

(a)

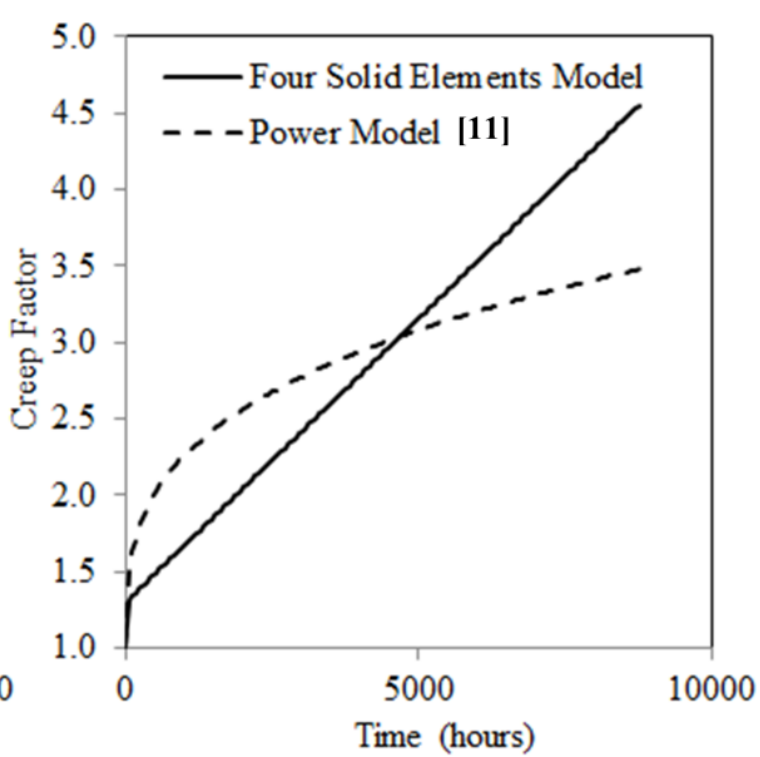

(b)

Figure 7. Predicted Creep Factor Given by the Power Function [10] and the Presented Model for Load Level of 50\%: (a) in Room Equiped with AC; and (b) in Room without AC

\section{Conclusions}

Analysis of creep constants of four solid elements model was performed in this study utilizing creep measurement of Walikukun (Schouthenia ovata) timber beams of a previous study. Some conclusions can be drawn as follows: 1 . Creep behavior given by both four solid elements model and phenomenological, in this case is power function, had good agreement during period of creep measurement, but they give different prediction of creep factor beyond this period; 2 . The power function of phenomenological model gave a more reasonable creep prediction than the four solid elements model; 3. As previous study suggested, modification to the creep equation developed by four solid elements is necessary when this equation is used for creep prediction beyond the measurement period; and 4. Under room condition equipped with $\mathrm{AC}$, the creep constants of four solid elements model showed a uniform trend in which they decrease with respect to the increase of stress level.

\section{References}

1. Lumantarna, B., Steven, and Budiono, D., Pengaruh Rangkak (creep) pada Bangunan Tinggi, Dimensi Teknik Sipil (in Indonesian), 5(1), 2003, pp. 29-38.

2. ASTM D6815, Standard Specification for Evaluation of Duration of Load and Creep Effect of Wood and Wood-Based Product, Annual Book of ASTM Standard, West Conshojocken, PA, 2002.
3. Bodig, J. and Jayne, B.A., Mechanical of Wood and Wood Composites, Kriger Publishing Company, Malabar Florida, 1982.

4. Holzer, S.M., Loferski, J.R., and Dillard, D.A., A Review of Creep in Wood: Concepts Relevant to Develop Long-Term Behavior Predictions for Wood Structures, Wood and Fiber Science, 21(4), 1989, pp. 376-392.

5. Findley, M.N., Lai, J.S., and Onaran, K., Creep and Relaxation of Nonlinear Viscoelastic Material with Introduction to Linear Viscoelastic, Dover Publication Inc., New York, 1989.

6. Ma, X., Wang, G., Jiang, Z., Xian, Y., and Li, H., Comparison of Bending Creep Behavior of Bamboo-Based Composites Manufactured by Two Types of Stacking Sequences, Bio Resources, 9(3), 2014, pp. 5461-5472.

7. Shen, Y. and Gupta, R., Evaluation of Creep Behavior of Structural Lumber in a Natural Environment, Forest Product Journal, 47(1), 1997, pp. 89-96.

8. Amino, Y., Bamboo-Precocious Wood Composite Beams: Bending Capacity for Long-Term Loading, Journal Bamboo and Rattan, 4(1), 2005, pp. 55-70.

9. Fidley, K.J., Tang, R.C., and Soltis, L.A., Creep Behavior Model for Structural Lumber, Journal of Structural Engineering, ASCE, 118(8), 1992, pp. 2261-2277.

10. Ma, Y., Li, X., Deng, B., and Luo, Y., Basic Study on Creep Properties of Eucalyptus Wood, Advanced Material Research, 911, 2014, pp. 232-237. 
11. Erlitasari, R., The Creep Behaviour of Walikukun Wood (Schouthenia ovata Korth), UnderGraduate Thesis, Department of Civil and Environmental Engineering, Gadjah Mada University, Yogyakarta, 2015.
12. Barati, R., Application of Excel Solver for Parameter Estimation of the Nonlinear Muskingum Models, KSCE Journal of Civil Engineering, 17(5), 2013, pp. 1139-1148. 